\title{
Early stages of pediatric bipolar disorder: retrospective analysis of a Czech inpatient sample
}

This article was published in the following Dove Press journal:

Neuropsychiatric Disease and Treatment

4 November 2015

Number of times this article has been viewed

\section{Michal Goetz' \\ Tomas Novak ${ }^{2}$ \\ Marie Vesela' \\ Zdenek Hlavka ${ }^{3}$ \\ Martin Brunovsky² \\ Michal Povazan ${ }^{4}$ \\ Radek Ptacek ${ }^{5}$ \\ Antonin Sebela ${ }^{2}$ \\ 'Department of Child Psychiatry, Second Faculty of Medicine, Motol University Hospital, Charles University in Prague, Prague, Czech Republic; ${ }^{2}$ National Institute of Mental Health, Klecany and Third Faculty of Medicine, Charles University in Prague, Prague, Czech Republic; ${ }^{3}$ Department of Probability and Mathematical Statistics, Faculty of Mathematics and Physics, Charles University in Prague, Prague, Czech Republic; ${ }^{4}$ Children's Department, Bohnice Psychiatric Hospital, Prague, Czech Republic; ${ }^{5}$ Department of Psychiatry, First Faculty of Medicine, General Teaching Hospital, Charles University in Prague, Czech Republic}

Correspondence: Michal Goetz Department of Child Psychiatry, Second Faculty of Medicine, Motol University Hospital, Charles University in Prague, V Uvalu 84, Prague 5,

I5006, Czech Republic

Tel +420728 7l8595

Email michal.goetz@lfmotol.cuni.cz
Background: Approximately $30 \%-60 \%$ of adults diagnosed with bipolar disorder (BD) report onset between the ages 15 and 19 years; however, a correct diagnosis is often delayed by several years. Therefore, investigations of the early features of BD are important for adequately understanding the prodromal stages of the illness.

Methods: A complete review of the medical records of 46 children and adolescents who were hospitalized for BD at two psychiatric teaching centers in Prague, Czech Republic was performed. Frequency of BD in all inpatients, age of symptom onset, phenomenology of mood episodes, lifetime psychiatric comorbidity, differences between very-early-onset $(<13$ years of age) and early-onset patients (13-18 years), and differences between the offspring of parents with and without BD were analyzed.

Results: The sample represents $0.83 \%$ of the total number of inpatients $(n=5,483)$ admitted during the study period at both centers. BD often started with depression $(56 \%)$, followed by hypomania (24\%) and mixed episodes (20\%). The average age during the first mood episode was 14.9 years (14.6 years for depression and 15.6 years for hypomania). Seven children (15\%) experienced their first mood episode before age 13 years (very early onset). Traumatic events, first-degree relatives with mood disorders, and attention deficit hyperactivity disorder were significantly more frequent in the very-early-onset group vs the early-onset group (13-18 years) $(P \leq 0.05)$. The offspring of bipolar parents were significantly younger at the onset of the first mood episode (13.2 vs 15.4 years; $P=0.02$ ) and when experiencing the first mania compared to the offspring of non-BD parents ( 14.3 vs 15.9 years; $P=0.03$ ). Anxiety disorders, substance abuse, specific learning disabilities, and attention deficit hyperactivity disorder were the most frequent lifetime comorbid conditions.

Conclusion: Clinicians must be aware of the potential for childhood BD onset in patients who suffer from recurrent depression, who have first-degree relatives with $\mathrm{BD}$, and who have experienced severe psychosocial stressors.

Keywords: children, adolescents, inpatients

\section{Introduction}

Bipolar disorder (BD) is a lifelong condition that highly impairs functioning and quality of life and increases the risk of a range of psychiatric and somatic comorbidities. For a long time, BD was rarely diagnosed in pediatric populations. However, studies have shown that approximately $30 \%-60 \%$ of individuals diagnosed with BD as adults retrospectively report an onset of illness prior to 20 years of age. ${ }^{1,2}$ Furthermore, $16 \%-27 \%$ of bipolar adults report that their first mood episode occurred prior to 13 years of age. ${ }^{3}$

Despite these findings, the diagnosis of BD may be delayed by up to 16 years if the first symptoms occurred in childhood and by 11 years in cases with adolescent onset. ${ }^{1,4}$ Childhood onset is also associated with a more difficult disease course ${ }^{5,6}$ and 
with several severe conditions, including substance abuse, suicidal behavior, and a greater number of mood episodes. ${ }^{7}$ Studying the initial stages of BD may therefore improve clinical practices regarding early detection of the illness and avoidance of diagnostic omissions or iatrogenic harm.

Over the past decade, considerable progress has been made in clinical studies of the onset and development of pediatric BD. Large longitudinal studies of bipolar offspring have been conducted worldwide, ${ }^{8-11}$ and their findings have been incorporated into the Diagnostic and Statistical Manual of Mental Disorders, Fifth Edition (DSM-5), via the inclusion of defined subthreshold syndromes. ${ }^{12}$

However, many issues remain unresolved. Studies differ regarding the frequency of prepubertal mania $\left(0 \%{ }^{9,13}\right.$ vs $1.2 \%$ in preschoolers $\left.{ }^{14}\right)$, as well as regarding the phenomenology and course of pediatric BD. ${ }^{15,16}$ While some researchers suggest that the main feature of pediatric mania is chronic irritability, ${ }^{16}$ others have observed an episodic course with depressive episodes typically preceding the onset of mania. $^{15}$

Furthermore, we still lack reliable methods of clearly differentiating between unipolar and bipolar depression. The staging model of BD suggests that episodes of minor mood disturbances in late childhood followed by major mood episodes in adolescence precede the onset of mania. ${ }^{17}$ Therefore, the early detection of depressive pediatric patients who are at risk for mania is of high clinical importance because it may lead to tailored treatment and prevent iatrogenic harm. Several clinical predictors have been identified in adults, including rapid onset of depressive symptoms, psychomotor retardation, mood-congruent psychotic features, family history of BD, and history of pharmacologically induced hypomania. ${ }^{18}$ However, few studies evaluating pediatric populations have been published. Conduct disorders, multigenerational family history of $\mathrm{BD}$, subthreshold $\mathrm{BD}$ symptoms, and baseline deficits in emotional regulation have been identified. ${ }^{19-21}$ In addition to these clinical parameters, neuroimaging has also been tested as a potentially objective method for the differential diagnosis of unipolar vs bipolar conditions. In an extensive review, Serafini et al found that reduced corpus callosum volume and increased rates of deep white matter hyperintensities were specific findings for pediatric $\mathrm{BD} ;{ }^{22}$ however, these neurobiological findings are far from being employed in regular clinical evaluations. Clinical research therefore represents an irreplaceable approach in improving diagnostics and treatment.

Surprising differences in BD prevalence in clinical samples have been described in recent reports. Differences among European countries are notably smaller than differences between Europe and the US. For example, in Germany, researchers found a $0.27 \%$ frequency of $\mathrm{BD},{ }^{23}$ whereas in Denmark, a $1.2 \%$ frequency was found. ${ }^{24}$ In Finland, the frequency was $1.7 \% .{ }^{25}$ Conversely, in the US, $10 \%$ of child inpatients and $10 \%$ of adolescents were reported to have BD in 1994 , compared to $36 \%$ and $26 \%$, respectively, in $2004 .^{26}$ The above-detailed discrepancies in published results and ongoing debates regarding $\mathrm{BD}$ presentation in pediatric populations motivated us to perform a retrospective analysis of an inpatient sample of children and adolescents from two leading centers of child psychiatry in the Czech Republic.

In all evaluated inpatients, we aimed to establish BD frequency, age of symptom onset, phenomenology of mood episodes, and lifetime psychiatric comorbidity. Furthermore, we analyzed differences between very-early-onset ( $<13$ years of age) and early-onset (13-18 years) patients, as well as differences between offspring from parents with and without BD. Finally, we assessed whether boys and girls differ in age of onset and lifetime comorbidity.

\section{Methods}

\section{Sample}

The current sample included children and adolescents who were hospitalized for BD at two sites: the Department of Child Psychiatry at Motol University Hospital (during the years 1997-2014; n=4,515) and the Children's Department of the Bohnice Psychiatric Hospital (during the years 2010-2014; n=968), both in Prague, Czech Republic.

\section{Inclusion criteria}

The following inclusion criteria were employed: age $<18$ years and Diagnostic and Statistical Manual of Mental Disorders, Fourth Edition (DSM-IV)-based diagnosis of BD. We included all subjects with BD, regardless of the severity of the disorder or the presence of other psychiatric comorbidities (excluding dependencies). Diagnosis was established using a semistructured clinical interview for mental disorders developed via institutional consensus at both centers and confirmed by the Board of Senior Child and Adolescent Psychiatrists, including the medical director of the Department of Child Psychiatry at Motol University Hospital and Children's Department at the Psychiatric Hospital Bohnice. However, this interview was not validated, and there is no national-language version of the clinical interviews that have been used in some other studies (eg, the Schedule for Affective Disorders and Schizophrenia for School-Age Children-Present and Lifetime ${ }^{27}$ ). The raters of this study reviewed all diagnoses according to the criteria in the Diagnostic and Statistical Manual of Mental Disorders, Fourth Edition (DSM-IV). ${ }^{28}$ 


\section{Exclusion criteria}

The only exclusion criterion was diagnosis of a mood disorder due to a medical condition or substance abuse.

\section{Procedure}

Two experienced child and adolescent psychiatrists performed a review of all entries of medical records of children and adolescents hospitalized for BD. Demographic data, family history of psychiatric illness, psychiatric diagnoses or symptoms preceding the onset of a typical mood episode, and Axis I comorbidities were collected. Stressors that are routinely evaluated in the Department of Child Psychiatry at Motol University Hospital and Children's department at the Psychiatric Hospital Bohnice based on psychiatric interviews were included in the analysis. These included death of a beloved parent, childhood abuse or neglect, and severe bullying. The Young Mania Rating Scale and Hamilton Rating Scale for Depression were used to rate mood and anxiety symptoms based on chart entries. Very-early-onset BD was defined as an onset of the first mood episode before the age of 13 years.

\section{Data analysis}

Statistical analysis was conducted using R statistical software. Two-sample Welch's $t$-tests with approximate degrees of freedom ${ }^{29}$ were used to compare mean ages between sexes, age-of-onset groups, and BD- and non-BD-offspring groups (the Shapiro-Wilk test was used to test normality assumptions). Associations between sex and categorical variables, as well as between age of onset and categorical variables, were investigated using Fisher's exact test. All analyses were tested at a significance level of 0.05 .

\section{Ethics}

The study was approved by the Institutional Review Board (IRB) at Motol University Hospital. The participants' parents provided informed written consent for analysis and publishing of clinical data collected during the hospitalization of their children.

\section{Results}

A total of 46 children and adolescents, of whom 21 (47\%) were girls, met the DSM-IV diagnostic criteria for BD. This sample represents $0.82 \%$ (Motol department) and $0.84 \%$ (Bohnice department) of the total number of child and adolescent psychiatric inpatients $(n=5,483)$ admitted during the study period at each center. In many of the patients, BD started with depression (56\%), followed by hypomania (24\%) and mixed episodes (20\%). The average age at the first mood episode was 14.9 years (14.6 years for depression and 15.6 years for hypomania) (for details, Table 1). The sociodemographic characteristics of our sample are shown in Table 2.

The majority of the patients $(n=37 ; 80 \%)$ initially underwent psychiatric treatment for a condition other than BD. The most frequent initial conditions that were diagnosed included major unipolar depression $(n=11$; $24 \%$ ), acute psychosis ( $\mathrm{n}=9 ; 20 \%)$, mixed/manic episode respectively $\mathrm{BD}(\mathrm{n}=9 ; 20 \%)$, adjustment disorder $(\mathrm{n}=6$; $13 \%)$, obsessive-compulsive disorder (OCD) $(n=3 ; 7 \%)$, attention deficit hyperactivity disorder (ADHD) $(n=2 ; 4 \%)$, anorexia nervosa $(n=2 ; 4 \%)$, anxiety disorder $(n=2 ; 4 \%)$, conduct disorder $(\mathrm{n}=1 ; 2 \%)$, and unspecified personality disorder $(\mathrm{n}=1 ; 2 \%)$.

Anxiety disorders (30\%), substance abuse (26\%), specific learning disabilities (19\%), and $\operatorname{ADHD}(15 \%)$ were the most frequent lifetime comorbid conditions. Multiple lifetime comorbidities were present in 15 patients (33\%). The lifetime comorbidity data are summarized in Table 3.

The phenomenology of the episodes that occurred during hospitalization and their associated features are shown in Table 4 and Figures 1-3. In comparing manic symptoms between manic and mixed episodes, no significant differences in frequency were identified, with the exception of physical aggressiveness (61\% in manic episodes vs $21 \%$ in mixed episodes; $P=0.04)$. No differences were found when comparing depressive symptoms between mixed and depressive episodes.

Table I Age characteristics of the total sample and of the subgroups with very-early-onset $(<\mid 3$ years $)$ and early-onset (I3-18 years) BD

\begin{tabular}{|c|c|c|c|c|c|c|}
\hline & \multicolumn{2}{|l|}{ Total sample $(n=46)$} & \multicolumn{2}{|c|}{ Very early onset $(n=7)$} & \multicolumn{2}{|l|}{ Early onset $(n=39)$} \\
\hline & Age (range), years & SD & Age (range), years & SD & Age (range), years & SD \\
\hline First psychiatric contact & I4.8 (9.4-I7.8) & 1.8 & $12.0(9.4-12.9)$ & 1.3 & $15.2(10.3-17.8)$ & 1.4 \\
\hline First mood episode & $14.9(9.0-18.0)$ & 1.7 & $12.0(9.0-12.9)$ & 1.4 & I5.5 (I3.3-17.9) & I.I \\
\hline First depression & $14.6(9.0-17.2)$ & 1.8 & $11.9(9.0-12.9)$ & 1.4 & $15.2(\mid 3.3-17.2)$ & 1.0 \\
\hline First mania & $15.6(11.5-18.0)$ & $\mathrm{I} .4$ & $13.8(\mid 1.5-16.0)$ & 1.4 & $16.0(13.7-18.0)$ & I.I \\
\hline BD diagnosed & $15.9(\mid 2.0-18.7)$ & 1.4 & $14.0(12.0-15.9)$ & 1.4 & $16.2(14.0-18.7)$ & I.I \\
\hline
\end{tabular}

Abbreviations: $\mathrm{BD}$, bipolar disorder; $\mathrm{SD}$, standard deviation. 
Table 2 Sociodemographic characteristics

\begin{tabular}{|c|c|c|}
\hline \multirow[t]{2}{*}{ Variable } & \multicolumn{2}{|c|}{$n=46$} \\
\hline & $\mathbf{n}$ & $\%$ \\
\hline \multicolumn{3}{|l|}{ Sex ratio } \\
\hline Girls & 21 & 45.6 \\
\hline \multicolumn{3}{|l|}{ Education } \\
\hline Secondary school & 10 & 21.7 \\
\hline High school & 13 & 28.2 \\
\hline Secondary school of engineering & II & 23.9 \\
\hline Vocational school & 8 & 17.3 \\
\hline Special education & 2 & 4.3 \\
\hline \multicolumn{3}{|l|}{ Family status } \\
\hline Complete & 28 & 60.8 \\
\hline Divorced & 16 & 34.7 \\
\hline Single parent & 2 & 4.3 \\
\hline \multicolumn{3}{|l|}{ Family history, first degree } \\
\hline Any affective disorder & 14 & 30.4 \\
\hline Bipolar disorder & 8 & 17.3 \\
\hline Psychosis & 3 & 6.5 \\
\hline Substance use & 3 & 6.5 \\
\hline Suicide attempt & 3 & 6.5 \\
\hline \multicolumn{3}{|l|}{ Family history, second degree } \\
\hline Affective disorder & 5 & 10.8 \\
\hline Substance use & 4 & 8.6 \\
\hline Suicide attempt & 4 & 8.6 \\
\hline Bipolar disorder & I & 2.1 \\
\hline Psychosis & I & 2.1 \\
\hline
\end{tabular}

\section{Comparison of very-early-onset vs early-onset groups}

Seven children (15\%) experienced their first mood episode before 13 years of age (three boys, four girls). The age characteristics of both groups related to psychiatric medical history are shown in Table 1.

The very-early-onset group had a significantly longer delay between age at first mood episode and age at diagnosis of $\mathrm{BD}(1.9 \pm 1.4$ years vs $0.7 \pm 0.7$ years; $P=0.046)$.

Table 3 Lifetime psychiatric comorbidity with bipolar disorder

\begin{tabular}{lll}
\hline DSM-IV disorder & $\mathbf{n}$ & $\%$ \\
\hline Anxiety disorders & 14 & 30 \\
Substance abuse & 12 & 26 \\
Specific learning disabilities & 9 & 19 \\
ADHD & 7 & 15 \\
OCD & 5 & 11 \\
Nocturnal enuresis & 4 & 9 \\
Eating disorder & 4 & 9 \\
Somatoform disorder & 3 & 7 \\
Tics & 2 & 4 \\
Intellectual disability & 2 & 4 \\
Autism spectrum disorder & 1 & 2 \\
Multiple comorbidity & 15 & 33 \\
\hline
\end{tabular}

Abbreviations: ADHD, attention deficit hyperactivity disorder; DSM-IV, Diagnostic and Statistical Manual of Mental Disorders, Fourth Edition; OCD, obsessive-compulsive disorder.
Table 4 Bipolar disorder subtypes and features of current episodes

\begin{tabular}{llc}
\hline Variable & $\mathbf{n}$ & $\%$ \\
\hline Bipolar disorder subtype & & \\
Bipolar I & 43 & 93.4 \\
Bipolar II & 3 & 6.5 \\
Characteristics of current episode & & \\
Manic & 16 & 34.7 \\
Nonpsychotic & 9 & 19.5 \\
Psychotic & 6 & 13.0 \\
Catatonic & $\mathrm{I}$ & 2.1 \\
Depressive & 7 & 15.2 \\
Nonpsychotic & 5 & 10.8 \\
Psychotic & $\mathrm{I}$ & 2.1 \\
Catatonic & $\mathrm{I}$ & 2.1 \\
Mixed (manic and depressive symptoms within I day) & 18 & 39.1 \\
Nonpsychotic & $\mathrm{II}$ & 23.9 \\
Psychotic & 4 & 8.6 \\
Catatonic & 3 & 6.5 \\
Very rapid cycling (cycling of episodes lasting I week) & 5 & 10.8 \\
Psychotic & $\mathrm{I}$ & 2.1 \\
\hline
\end{tabular}

The difference in the delay between age at first depression and age at first mania between the groups was not significant ( $2.0 \pm 1.2$ years vs $0.9 \pm 0.8$ years; $P=0.06$ ).

Comparisons of the clinical variables between the groups revealed that the very-early-onset group more frequently experienced traumatic events $(P=0.03)$, more frequently experienced ADHD as a first psychiatric diagnosis $(P=0.02)$, and were more likely to have a first-degree relative with a mood disorder $(P=0.02)$ compared to the adolescent-onset group (for details, Table 5).

\section{Comparison of offspring from parents with and without $B D$}

One-third of our patients $(n=14 ; 30 \%)$ had a first-degree relative suffering from a mood disorder. Eight patients (17\%) had a parent with BD. The offspring of a bipolar parent or parents had significantly earlier ages of BD onset (13.2 vs 15.4 years; $P=0.03$ ) and earlier onset of mania (14.3 vs 15.9 years; $P=0.03$ ) compared to the offspring of parents without BD; however, there were no differences in age of depression onset (13.3 vs 15.0 years; $P=0.12$ ). Furthermore, the groups differed regarding the age at first psychiatric contact (13.1 vs 15.2 years; $P=0.045$ ), and there was a trend toward earlier age at initial $\mathrm{BD}$ diagnosis ( 14.7 vs 16.1 years; $P=0.053$ ) (Table 6).

\section{Sex differences}

We found that boys had a significantly greater number of neurodevelopmental lifetime diagnoses (ADHD and/or learning disabilities) than girls ( $\mathrm{n}=10[40 \%]$ vs $\mathrm{n}=2[10 \%] ; P=0.04)$, while girls had a greater number of eating disorders ( $\mathrm{n}=0 \mathrm{vs}$ 


\section{Symptoms during manic episodes (\%)}

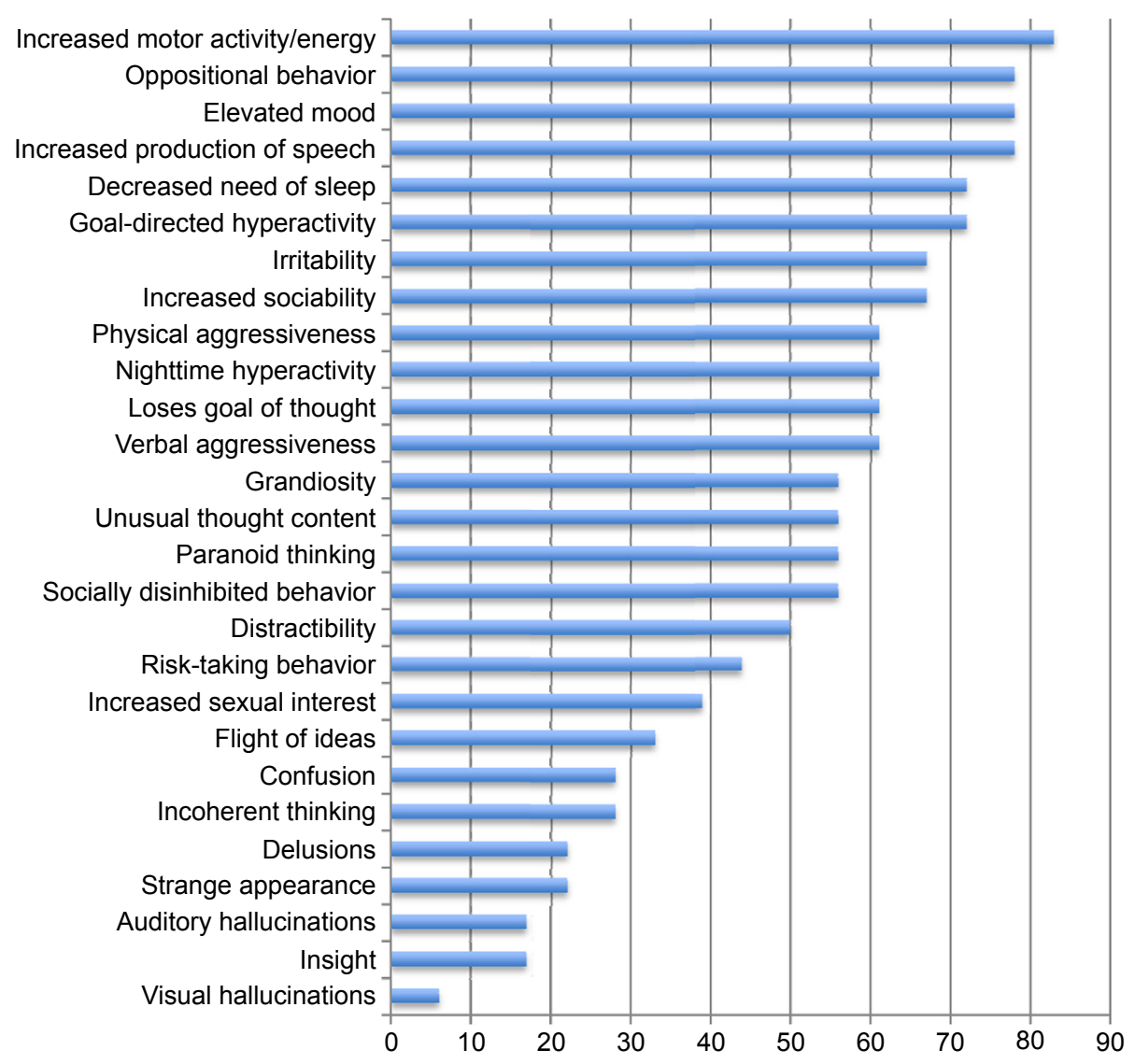

Figure I Frequency of symptoms during manic episodes in pediatric inpatients with bipolar disorder, $\mathrm{n}=\mid \mathbf{6}$.

$\mathrm{n}=4 ; 19 \% ; P=0.04)$ and higher frequency of alcohol abuse ( $\mathrm{n}=0$ vs $\mathrm{n}=4 ; 19 \% ; P=0.04$ ). No significant sex-related differences were established for age at onset of mood episodes, mood episode features, family history, or other characteristics (for details, Table 7).

\section{Discussion}

In the current study, we aimed to describe the early features and development of BD by analyzing data corresponding to an inpatient sample of adolescents diagnosed with BD.

The prevalence of BD diagnosis in children and adolescents hospitalized with other diagnoses was $0.83 \%$ at both study centers, which is similar to results from a study conducted in Denmark (1.2\%). ${ }^{24}$ However, these findings differ greatly from a similar study in the US, where the prevalence of $\mathrm{BD}$ in children and adolescents discharged from inpatient units was $10 \%$ in 1996 and $36 \%$ in $2004 .{ }^{26}$ Additionally, in retrospective studies, the rates of childhood-onset BD differ between Europe and the US. Post et al found that childhood- or adolescent-onset bipolar illness was reported by $61 \%$ of those in a US cohort but only by $30 \%$ of those in a cohort including participants from the Netherlands and Germany. ${ }^{30,31}$ The higher rate reported in the US cohort may be due to expanded diagnostic criteria or to diagnosis of BD in children with chronic irritability, which was not previously considered a BD symptom. However, it may also reflect environmental and genetic factors. Post et al found that the substantially higher incidence of childhood-onset BD in the US sample was accompanied by a twofold-higher frequency of positive family history of BD compared to that in the European samples..$^{30,31}$

The influence of family history of affective disorders on age at $\mathrm{BD}$ onset was recently reported. ${ }^{7}$ In an extensive review, it was found that a childhood-onset group, but not an adolescent-onset group, had significantly higher rates of first-degree relatives with mood disorders than an adultonset group. ${ }^{7}$ Similarly, Post et al found that an early age at BP onset was associated with increased parental history of affective disorder. ${ }^{31}$ We have replicated this finding in our study. Furthermore, we found that offspring of bipolar parents had significantly earlier average ages of first mood episode (13.2 vs 15.4 years) and mania (14.3 vs 15.9 years) than did offspring of non-bipolar parents. 


\section{Frequency of symptoms during mixed episodes (\%)}

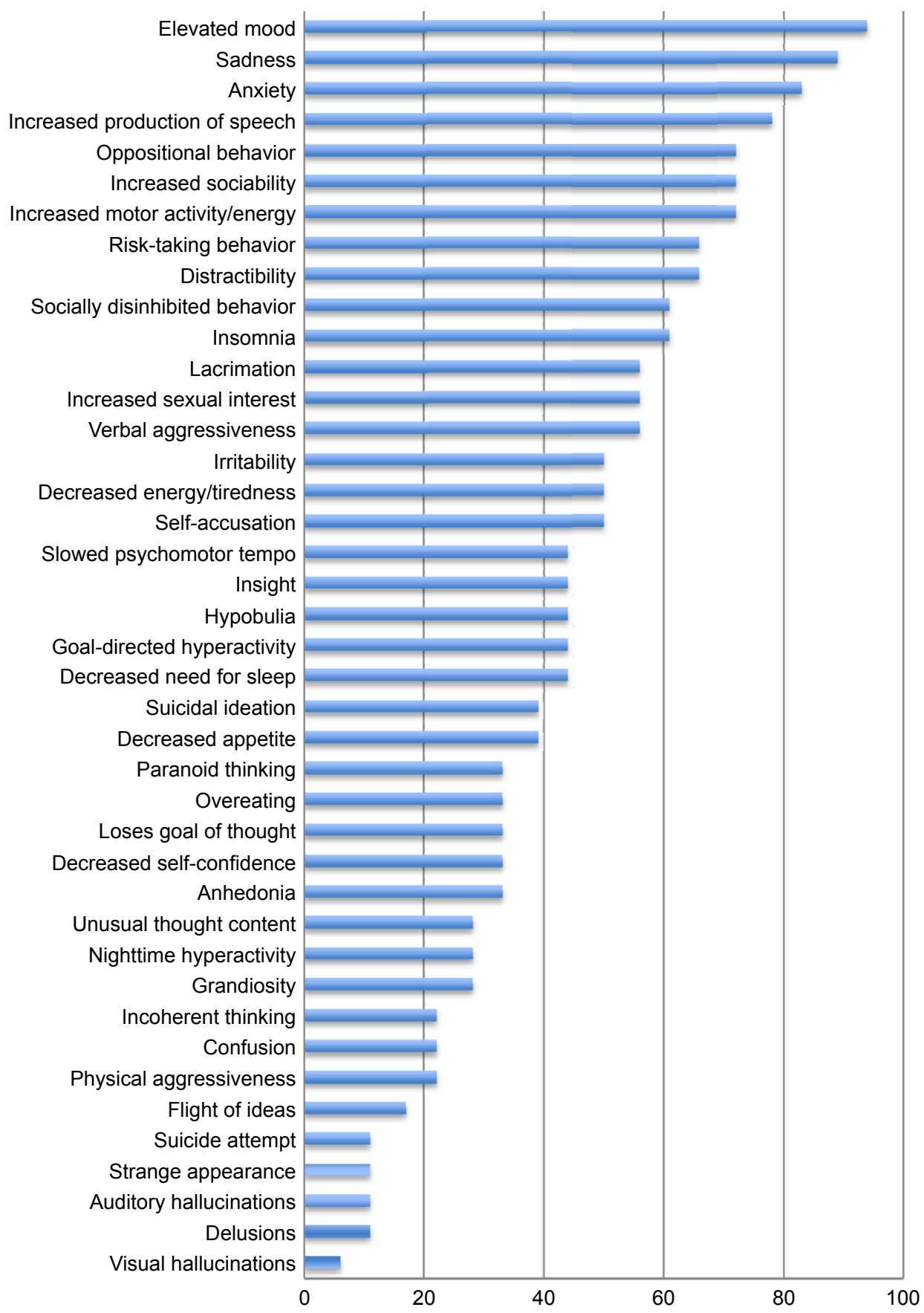

Figure 2 Frequency of symptoms during mixed episodes in pediatric inpatients with bipolar disorder, $\mathrm{n}=18$.

In addition to these genetic factors, it has also been suggested that psychosocial stressors might not only affect the course of BD but also the age at BD onset. ${ }^{32}$ In addition to stressors such as sexual abuse, neglect, and death of a beloved parent, we included peer bullying, as this is a severe stressor that has been associated with increased risk of a wide range of psychopathologies..$^{33} \mathrm{We}$ found that severe traumatic events were significantly more likely to be present in the medical histories of the very-early-onset group than in those of the early-onset group. This finding corresponds to a recent study that demonstrated a significant inverse relationship between age at onset and number of traumatic events experienced. ${ }^{34}$ However, several other stressors that were not evaluated in our study (eg, family stress) have been indicated to be involved in the course of $\mathrm{BD}$, especially in its initial stages. ${ }^{18}$

Manic episode frequency during childhood is another matter of discussion. Since the creation of Kraepelin's 


\section{Symptoms during depressive episodes (\%)}

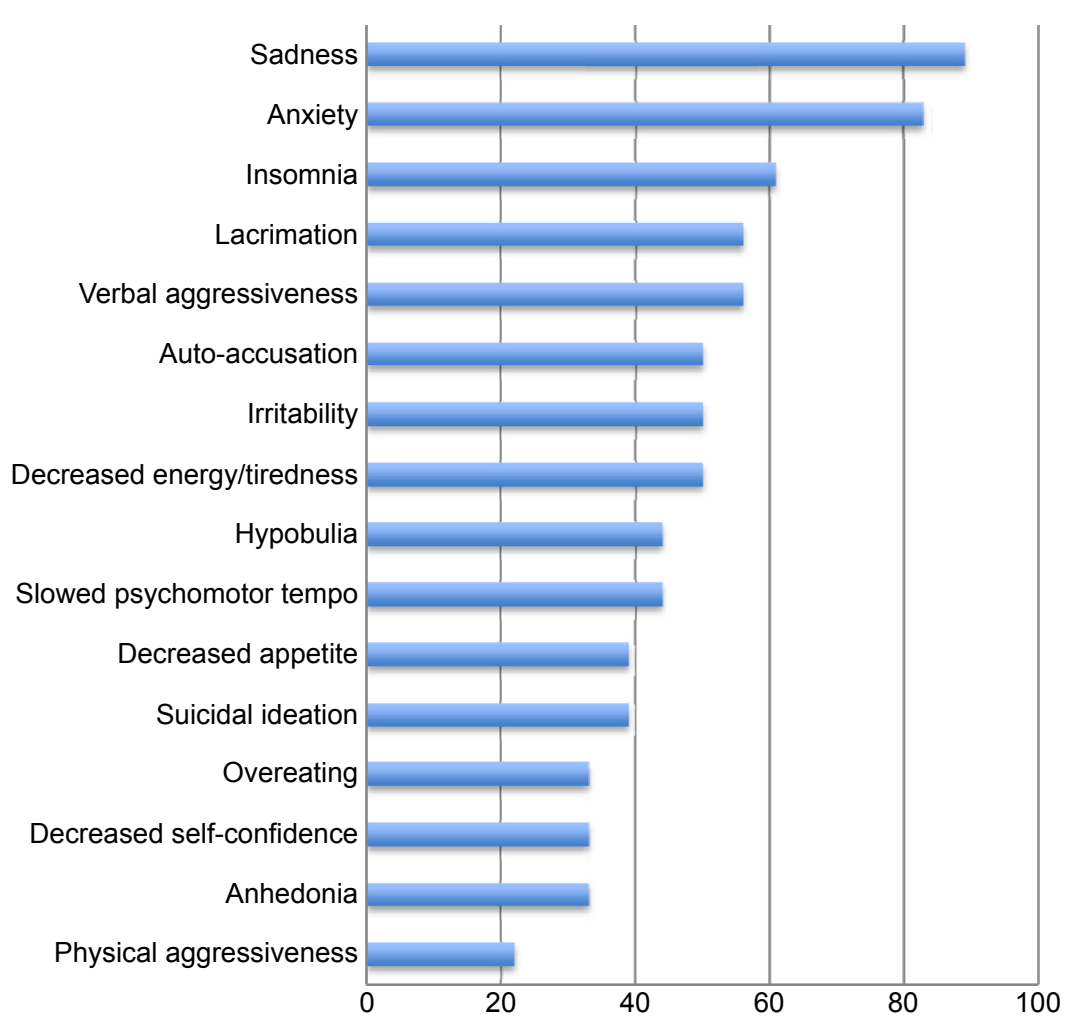

Figure 3 Frequency of symptoms during depressive episodes in pediatric inpatients with bipolar disorder, $\mathrm{n}=7$.

classification, it has been agreed that manic episodes may occur at prepubertal ages; however, for decades, this phenomenon was considered rare..$^{35}$ In recent studies, several authors have suggested that mania is not uncommon in child and adolescent populations. ${ }^{14,36}$ Birmaher et al in a study of high-risk offspring found hypo/mania in $9.7 \%$ of children with bipolar disorder less than 12 years of age and the diagnosis of $\mathrm{BD}$ not otherwise specified was established in $46 \%$ of children with bipolar disorder before they reached 12 years of age. ${ }^{10}$ Our current data correspond with the more classic view. We found only one case (2\%) of mania occurring before 12 years of age (an 11.5-year-old boy with comorbid autism spectrum disorder) and three cases before 13 years of age (6\%).

In a mixed inpatient and outpatient sample of pediatric bipolar patients, Lázaro et al analyzed differences in diagnostic delays between a group with $\mathrm{BD}$ onset before 13 years of age and a group with later onset. ${ }^{36}$ They found that the former group differed significantly from the latter (1.2 vs 0.8 years).$^{36}$ Our results are concordant with their findings (1.9 vs 0.7 years). The delay in diagnosing BD in our group is attributable to the delay between first depression and first mania ( 2 years).

In the majority of our patients (56\%), bipolar illness started with depression. This is similar to findings from the Systematic Treatment Enhancement Program for
Bipolar Disorder (STEP-BD), in which $63.5 \%$ of first mood episodes were depressive in a very-early-onset ( $<13$ years) group and $58.7 \%$ were depressive in an early-onset group (13-18 years). ${ }^{3}$ However, it must be noted that some patients may experience a very brief early hypomanic episode but cycle heavily on the depressive pole later on.$^{37}$ Nevertheless, prospective studies support the notion that, in most cases, BD starts with several depressive episodes before mood elevation. Duffy et al found that $97 \%$ of high-risk subjects who developed BD experienced a first mood episode that was either minor or major depression, ${ }^{15}$ and Hillegers et al reported that $91 \%$ of subjects had depression at onset. ${ }^{9}$

The most common comorbid conditions in our sample were anxiety disorders. This corresponds with findings from a representative high-risk-offspring study. ${ }^{13}$ Additionally, higher rates of anxiety disorders have been reported in studies such as STEP-BD, where anxiety disorders were present in $54 \%-69 \%$ of patients. ${ }^{3}$ The presence of anxiety disorders was found to be a strong risk factor for later onset of BD. ${ }^{13}$

We found that $19 \%$ of patients in our sample also suffered from OCD in their lifetime. This finding corresponds with those from STEP-BD, where BD and OCD comorbidity was found in $13.5 \%$ of patients $<13$ years old at onset and in $8.7 \%$ of a 13- to 18-year-old onset group. ${ }^{3}$ Both epidemiological 
Table 5 Comparison of clinical characteristics between veryearly-onset $(<13$ years) and early-onset (13-18 years) bipolar disorder patients

\begin{tabular}{|c|c|c|c|}
\hline & $\begin{array}{l}\begin{array}{l}\text { Very early } \\
\text { onset }(n=7)\end{array} \\
\end{array}$ & $\begin{array}{l}\begin{array}{l}\text { Early onset } \\
(n=39)\end{array} \\
\end{array}$ & $P$-value ${ }^{a}$ \\
\hline & n (\%) & n (\%) & \\
\hline \multicolumn{4}{|l|}{ Family status } \\
\hline Divorced & $3(43)$ & $13(33)$ & 0.68 \\
\hline Single parent & $\mathrm{I}(14)$ & I (3) & 0.31 \\
\hline $\begin{array}{l}\text { First-degree relative with } \\
\text { mood disorder }\end{array}$ & $5(7 \mid)$ & $9(23)$ & 0.02 \\
\hline Personal history of trauma & $4(57)$ & $6(15)$ & 0.03 \\
\hline \multicolumn{4}{|l|}{ First psychiatric diagnosis } \\
\hline ADHD & $2(29)$ & 0 & 0.02 \\
\hline Major depression & $2(29)$ & $10(26)$ & 1.0 \\
\hline Manic episode & I (I4) & $7(18)$ & 1.0 \\
\hline Adjustment disorder & $2(29)$ & $4(10)$ & 0.22 \\
\hline Psychotic disorder & 0 & $9(23)$ & 0.32 \\
\hline Anxiety disorder & 0 & $2(5)$ & 1.0 \\
\hline Eating disorder & 0 & $2(5)$ & 1.0 \\
\hline Conduct disorder & 0 & $\mathrm{I}(3)$ & 1.0 \\
\hline $\begin{array}{l}\text { Unspecified personality } \\
\text { disorder }\end{array}$ & 0 & I (3) & 1.0 \\
\hline \multicolumn{4}{|c|}{ Polarity of the first mood episode } \\
\hline Depressive & $5(7 I)$ & $21(54)$ & 0.45 \\
\hline Manic & I (14) & $10(26)$ & 0.66 \\
\hline Mixed & I (14) & $8(2 \mathrm{I})$ & 1.0 \\
\hline \multicolumn{4}{|l|}{ Lifetime comorbidity } \\
\hline Any comorbidity & $6(86)$ & $26(66)$ & 0.41 \\
\hline Substance abuse & $3(42)$ & $9(23)$ & 0.36 \\
\hline $\mathrm{ADHD}$ & $2(29)$ & $5(13)$ & 0.29 \\
\hline $\begin{array}{l}\text { Specific learning } \\
\text { disabilities }\end{array}$ & $2(29)$ & $7(18)$ & 0.61 \\
\hline Tics & $0(0)$ & $2(5)$ & 1.0 \\
\hline OCD & $0(0)$ & $5(13)$ & 1.0 \\
\hline Anxiety disorder & $2(29)$ & $12(3 \mid)$ & 1.0 \\
\hline Eating disorder & I (14) & $2(5)$ & 0.40 \\
\hline Suicide attempt & I (I4) & $5(\mid 3)$ & 1.0 \\
\hline
\end{tabular}

Note: 'Fisher's exact test.

Abbreviations: ADHD, attention deficit hyperactivity disorder; $O C D$, obsessivecompulsive disorder.

and clinical studies have reported that OCD and BD coexist in $11 \%-21 \%$ of adults. ${ }^{38}$

The prevalence of ADHD (28\%) as a comorbidity in our sample corresponds with findings from other studies of the phenomenology of pediatric BD $\left(21 \%,{ }^{39} 38 \%{ }^{40}\right)$. However, the relationship between $\mathrm{BD}$ and $\mathrm{ADHD}$ is still unclear. Duffy reviewed the nature of this relationship in findings from prospectively assessed high-risk-offspring studies. ${ }^{41}$ She concluded that a clinical diagnosis of childhood ADHD is not a reliable predictor of the development of $\mathrm{BD}$; rather, the symptom of inattention may be part of a mixed clinical presentation during the early stages of evolving BD, appearing alongside anxiety and depressive symptoms. ${ }^{41}$ Conversely, an analysis of 61,187 individuals with ADHD who were included in a Swedish longitudinal national register found that subjects diagnosed with ADHD were 24 times more likely to be diagnosed with $\mathrm{BD}$ in adulthood compared with those in a control group. ${ }^{42}$ Furthermore, first-degree relatives of subjects with ADHD were more likely to have been diagnosed with BD than first-degree relatives of control group participants, suggesting the existence of shared genetic factors between these disorders. ${ }^{42}$ This finding does not necessarily conflict with the conclusions of Duffy's review. ${ }^{41}$ Although ADHD is categorically defined, there is also evidence supporting the notion that ADHD is an extreme presentation of a continuous trait. ${ }^{43}$ Thus, the inattention symptoms that were present in the studies reviewed by Duffy may be part of a genetic and etiologic continuum of ADHD that was also identified in other offspring studies. ${ }^{44,45}$

In comparing differences between the sexes regarding symptoms and comorbidity, we found that boys had a greater number of neurodevelopmental lifetime comorbidities, including ADHD (respectively hyperkinetic disorder of activity and attention and hyperkinetic conduct disorder with disruptive symptoms and irritability) and learning disabilities, compared to girls. Although a previous study did not find significant differences between boys and girls in the manifestation of $\mathrm{BD},{ }^{46}$ our current results correspond with the findings of several high-risk-offspring studies in which a greater number of disruptive symptoms were found in boys than in girls. ${ }^{47,48}$ Therefore, it is unclear whether irritability as a hallmark symptom of pediatric BD may be generalized

Table 6 Comparison of age characteristics between offspring from bipolar parents (BD parent) and those of patients without family histories of BD (non-BD parent)

\begin{tabular}{|c|c|c|c|c|c|}
\hline & \multicolumn{2}{|l|}{ BD parent $(n=8)$} & \multicolumn{2}{|c|}{ Non-BD parent $(n=38)$} & \multirow[t]{2}{*}{$P$-value ${ }^{a}$} \\
\hline & Age (range), years & SD & Age (range), years & SD & \\
\hline First psychiatric contact & $13.1(9.4-17.0)$ & 2.3 & $15.2(10.3-17.8)$ & 1.4 & 0.045 \\
\hline First mood episode & $13.2(9.0-16.7)$ & 2.2 & $15.4(\mid 1.6-18.0)$ & 1.3 & 0.03 \\
\hline First depression & | $3.3(9.0-17.0)$ & 2.4 & $15.0(|1.6-| 7.2)$ & 1.3 & 0.12 \\
\hline First mania & $14.3(\mid 1.5-16.7)$ & 1.6 & $15.9(12.9-18.0)$ & I.I & 0.03 \\
\hline BD diagnosed & $14.7(\mid 2.0-17.4)$ & 1.7 & $16.1(12.0-18.8)$ & 1.2 & 0.053 \\
\hline
\end{tabular}

Note: 'Welch's unequal variances t-test.

Abbreviations: BD, bipolar disorder; SD, standard deviation. 
Table 7 Comparison of age characteristics between boys and girls

\begin{tabular}{|c|c|c|c|c|c|}
\hline & \multicolumn{2}{|l|}{ Girls $(n=2 I)$} & \multicolumn{2}{|l|}{ Boys $(n=25)$} & \multirow[t]{2}{*}{$P$-value ${ }^{a}$} \\
\hline & Age (range), years & $\overline{\text { SD }}$ & Age (range), years & $\overline{\text { SD }}$ & \\
\hline First psychiatric contact & $15.2(9.4-17.2)$ & 1.6 & $14.4(11.0-17.8)$ & 2.1 & 0.18 \\
\hline First mood episode & $15.1(11.6-17.9)$ & 1.9 & $14.8(9.0-17.8)$ & 1.6 & 0.58 \\
\hline First depression & $14.6(11.6-17.0)$ & 2.0 & $14.7(9.0-17.2)$ & 1.5 & 0.81 \\
\hline First mania & $15.7(12.9-17.9)$ & 1.5 & $15.6(\mid 1.5-18.0)$ & 0.8 & 0.84 \\
\hline BD diagnosed & $15.9(12.9-17.9)$ & 1.5 & $15.9(12.0-18.7)$ & 1.3 & 0.84 \\
\hline
\end{tabular}

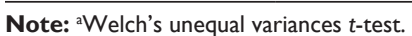

Abbreviations: BD, bipolar disorder; SD, standard deviation.

to the entire pediatric population or whether it is specific to bipolar boys with a high comorbidity of ADHD and/ or oppositional defiant disorder.

\section{Limitations}

The current study possessed several limitations that must be taken into consideration. Our data on patient medical history are based on retrospective reports by patients, parents, and previous medical charts. This may lead to the omission of subthreshold manifestations of mental disorders. Although institutional consensus-based, semi-structured clinical interviews were used, these were not validated. Furthermore, the included patients were not followed up; therefore, the possibility that their diagnoses were eventually changed to reflect an alternative condition cannot be excluded. Finally, we only enrolled patients with diagnosed hypomania. Therefore, bipolar patients who had already been treated for depression but did not experience an onset of first mania until after the age of 18 years were not captured by our methodology.

\section{Conclusion}

Compared to studies conducted in the US, we found a lower prevalence of BD among children and adolescent psychiatric inpatients. In the majority of our sample, the first episode of mania occurred during adolescence. However, clinicians must be highly aware of the possibility of BD onset during childhood in patients who suffer from early depression, have a first-degree relative with $\mathrm{BD}$, or who have experienced severe psychosocial stressors.

\section{Acknowledgments}

This study was supported by research grant IGA (Internal Grant Agency of the Czech Ministry of Health) NT 13337-4/2012, and by the project (Ministry of Health, Czech Republic) for conceptual development of research organization 00064203 (University Hospital Motol, Prague, Czech Republic). Part of the study was presented at the 60th Annual Meeting of the American Academy of Child and Adolescent Psychiatry; October 22-27, 2013; Orlando, FL, USA.

\section{Disclosure}

The authors report no conflicts of interest in this work.

\section{References}

1. Egeland JA, Hostetter AM, Pauls DL, Sussex JN. Prodromal symptoms before onset of manic-depressive disorder suggested by first hospital admission histories. J Am Acad Child Adolesc Psychiatry. 2000; 39(10):1245-1252.

2. Morselli PL, Elgie R; GAMIAN-Europe. GAMIAN-Europe/BEAM survey I - global analysis of a patient questionnaire circulated to 3450 members of 12 European advocacy groups operating in the field of mood disorders. Bipolar Disord. 2003;5(4):265-278.

3. Perlis RH, Miyahara S, Marangell LB, et al; STEP-BD Investigators. Long-term implications of early onset in bipolar disorder: data from the first 1000 participants in the systematic treatment enhancement program for bipolar disorder (STEP-BD). Biol Psychiatry. 2004;55(9):875-881.

4. Leboyer M, Henry C, Paillere-Martinot ML, Bellivier F. Age at onset in bipolar affective disorders: a review. Bipolar Disord. 2005;7(2): 111-118.

5. Carlson GA, Bromet EJ, Driessens C, Mojtabai R, Schwartz JE. Age at onset, childhood psychopathology, and 2-year outcome in psychotic bipolar disorder. Am J Psychiatry. 2002;159(2):307-309.

6. Leverich GS, Post RM, Keck PE Jr, et al. The poor prognosis of childhood-onset bipolar disorder. J Pediatr. 2007;150(5):485-490.

7. Holtzman JN, Miller S, Hooshmand F, et al. Childhood-compared to adolescent-onset bipolar disorder has more statistically significant clinical correlates. J Affect Disord. 2015;179:114-120.

8. Duffy A, Alda M, Crawford L, Milin R, Grof P. The early manifestations of bipolar disorder: a longitudinal prospective study of the offspring of bipolar parents. Bipolar Disord. 2007;9(8):828-838.

9. Hillegers MH, Reichart CG, Wals M, Verhulst FC, Ormel J, Nolen WA. Five-year prospective outcome of psychopathology in the adolescent offspring of bipolar parents. Bipolar Disord. 2005;7(4):344-350.

10. Birmaher B, Axelson D, Monk K, et al. Lifetime psychiatric disorders in school-aged offspring of parents with bipolar disorder: the Pittsburgh Bipolar Offspring study. Arch Gen Psychiatry. 2009;66(3):287-296.

11. Egeland JA, Endicott J, Hostetter AM, Allen CR, Pauls DL, Shaw JA. A 16-year prospective study of prodromal features prior to BPI onset in well Amish children. J Affect Disord. 2012;142(1-3):186-192.

12. American Psychiatric Association. Diagnostic and Statistical Manual of Mental Disorders, Fifth Edition. Washington: American Psychiatric Association; 2013.

13. Duffy A, Alda M, Hajek T, Grof P. Early course of bipolar disorder in high-risk offspring: prospective study. Br J Psychiatry. 2009;195(5): 457-458.

14. Birmaher B, Axelson D, Goldstein B, et al. Psychiatric disorders in preschool offspring of parents with bipolar disorder: the Pittsburgh Bipolar Offspring Study (BIOS). Am J Psychiatry. 2014;167(3): 321-330.

15. Duffy A, Alda M, Hajek T, Sherry SB, Grof P. Early stages in the development of bipolar disorder. J Affect Disord. 2010;121(1-2): $127-135$. 
16. Biederman J, Faraone S, Wozniak J, Mick E, Kwon A, Aleardi M. Further evidence of unique developmental phenotypic correlates of pediatric bipolar disorder: findings from a large sample of clinically referred preadolescent children assessed over the last 7 years. $J$ Affect Disord. 2004;82 Suppl 1:S45-S58.

17. Duffy A, Horrocks J, Doucette S, Keown-Stoneman C, McCloskey S, Grof P. The developmental trajectory of bipolar disorder. Br J Psychiatry. 2014;204(2):122-128.

18. Goodwin FK, Jamison KR. Manic-Depressive Illness: Bipolar Disorders and Recurrent Depression. 2nd ed. New York: Oxford University Press; 2007.

19. Strober M, Lampert C, Schmidt S, Morrell W. The course of major depressive disorder in adolescents: I. Recovery and risk of manic switching in a follow-up of psychotic and nonpsychotic subtypes. $J \mathrm{Am}$ Acad Child Adolesc Psychiatry. 1993;32(1):34-42.

20. Geller B, Fox LW, Clark KA. Rate and predictors of prepubertal bipolarity during follow-up of 6- to 12-year-old depressed children. $J \mathrm{Am}$ Acad Child Adolesc Psychiatry. 1994;33(4):461-468.

21. Biederman J, Wozniak J, Tarko L, et al. Re-examining the risk for switch from unipolar to bipolar major depressive disorder in youth with ADHD: a long term prospective longitudinal controlled study. $J$ Affect Disord. 2014;152-154:347-351.

22. Serafini G, Pompili M, Borgwardt S, et al. Brain changes in earlyonset bipolar and unipolar depressive disorders: a systematic review in children and adolescents. Eur Child Adolesc Psychiatry. 2014; 23(11):1023-1041.

23. Holtmann M, Duketis E, Poustka L, Zepf FD, Poustka F, Bölte S. Bipolar disorder in children and adolescents in Germany: national trends in the rates of inpatients, 2000-2007. Bipolar Disord. 2010;12(2):155-163.

24. Thomsen PH, Møller LL, Dehlholm B, Brask BH. Manic-depressive psychosis in children younger than 15 years: a register-based investigation of 39 cases in Denmark. Acta Psychiatr Scand. 1992;85(5):401-406.

25. Sourander A. Combined psychopharmacological treatment among child and adolescent inpatients in Finland. Eur Child Adolesc Psychiatry. 2004;13(3):179-184.

26. Blader JC, Carlson GA. Increased rates of bipolar disorder diagnoses among U.S. child, adolescent, and adult inpatients, 1996-2004. Biol Psychiatry. 2007;62(2):107-114.

27. Kaufman J, Birmaher B, Brent D, et al. Schedule for Affective Disorders and Schizophrenia for School-Age Children-Present and Lifetime Version (K-SADS-PL): initial reliability and validity data. $J$ Am Acad Child Adolesc Psychiatry. 1997;36:980-988.

28. American Psychiatric Association. Diagnostic and Statistical Manual of Mental Disorders, Fourth Edition, Text Revision., American Psychiatric Association; 2000.

29. Rasch D, Teuscher F, Guiard V. How robust are tests for two independent samples? J Stat Plan Inference. 2007;137(8):2706-2720.

30. Post RM, Luckenbaugh DA, Leverich GS, et al. Incidence of childhood-onset bipolar illness in the USA and Europe. Br J Psychiatry. 2008;192(2):150-151.

31. Post RM, Leverich GS, Kupka R, et al. Increased parental history of bipolar disorder in the United States: association with early age of onset. Acta Psychiatr Scand. 2014;129(5):375-382.

32. Post RM, Leverich GS. The role of psychosocial stress in the onset and progression of bipolar disorder and its comorbidities: the need for earlier and alternative modes of therapeutic intervention. Dev Psychopathol. 2006;18(4):1181-1211.

Neuropsychiatric Disease and Treatment

\section{Publish your work in this journal}

Neuropsychiatric Disease and Treatment is an international, peerreviewed journal of clinical therapeutics and pharmacology focusing on concise rapid reporting of clinical or pre-clinical studies on a range of neuropsychiatric and neurological disorders. This journal is indexed on PubMed Central, the 'PsycINFO' database and CAS,
33. Kim JW, Lee K, Lee YS, et al. Factors associated with group bullying and psychopathology in elementary school students using child-welfare facilities. Neuropsychiatr Dis Treat. 2015;11:991-998.

34. Anand A, Koller DL, Lawson WB, Gershon ES, Nurnberger JI; BiGS Collaborative. Genetic and childhood trauma interaction effect on age of onset in bipolar disorder: an exploratory analysis. $J$ Affect Disord. 2015;179:1-5

35. Carlson GA, Glovinsky I. The concept of bipolar disorder in children: a history of the bipolar controversy. Child Adolesc Psychiatr Clin N Am. 2009;18(2):257-271

36. Lázaro L, Castro-Fornieles J, de la Fuente JE, Baeza I, Morer A, Pàmias M. Differences between prepubertal- versus adolescent- onset bipolar disorder in a Spanish clinical sample. Eur Child Adolesc Psychiatry. 2007;16(8):510-516.

37. Hinz M, Stein A, Uncini T. A pilot study differentiating recurrent major depression from bipolar disorder cycling on the depressive pole. Neuropsychiatr Dis Treat. 2010;6:741-747.

38. Amerio A, Odone A, Liapis CC, Ghaemi SN. Diagnostic validity of comorbid bipolar disorder and obsessive-compulsive disorder: a systematic review. Acta Psychiatr Scand. 2014;129(5):343-358.

39. Soutullo CA, Chang KD, Díez-Suárez A, et al. Bipolar disorder in children and adolescents: international perspective on epidemiology and phenomenology. Bipolar Disord. 2005;7(6):497-506.

40. Masi G, Perugi G, Millepiedi S, et al. Developmental differences according to age at onset in juvenile bipolar disorder. J Child Adolesc Psychopharmacol. 2006;16(6):679-685.

41. Duffy A. The nature of the association between childhood ADHD and the development of bipolar disorder: a review of prospective high-risk studies. Am J Psychiatry. 2012;169(12):1247-1255.

42. Larsson H, Rydén E, Boman M, Långström N, Lichtenstein P, Landén M. Risk of bipolar disorder and schizophrenia in relatives of people with attention-deficit hyperactivity disorder. Br J Psychiatry. 2013; 203(2):103-106.

43. Larsson $\mathrm{H}$, Anckarsater H, Råstam $\mathrm{M}$, Chang Z, Lichtenstein P. Childhood attention-deficit hyperactivity disorder as an extreme of a continuous trait: a quantitative genetic study of 8,500 twin pairs. J Child Psychol Psychiatry. 2012;53(1):73-80.

44. Chang KD, Steiner H, Ketter TA. Psychiatric phenomenology of child and adolescent bipolar offspring. J Am Acad Child Adolesc Psychiatry. 2000;39(4):453-460.

45. Singh MK, DelBello MP, Stanford KE, et al. Psychopathology in children of bipolar parents. J Affect Disord. 2007;102(1-3):131-136.

46. Biederman J, Kwon A, Wozniak J, et al. Absence of gender differences in pediatric bipolar disorder: findings from a large sample of referred youth. $J$ Affect Disord. 2004;83(2-3):207-214.

47. Radke-Yarrow M, Nottelmann E, Martinez P, Fox MB, Belmont B. Young children of affectively ill parents: a longitudinal study of psychosocial development. J Am Acad Child Adolesc Psychiatry. 1992; 31(1):68-77.

48. Wals M, Hillegers MH, Reichart CG, Ormel J, Nolen WA, Verhulst FC. Prevalence of psychopathology in children of a bipolar parent. $J$ Am Acad Child Adolesc Psychiatry. 2001;40(9):1094-1102. and is the official journal of The International Neuropsychiatric Association (INA). The manuscript management system is completely online and includes a very quick and fair peer-review system, which is all easy to use. Visit http://www.dovepress.com/testimonials.php to read real quotes from published authors. 